\title{
Интраоперативна ятрогенна лезия на нервус ларингеус рекуренс и възстановяване целостта мy c Prolene 7.0 - клиничен случай
}

\author{
Р. Пандев ${ }^{1}$, Д. Досков², Сп. Тодоров², А. Кузи ${ }^{1}$ \\ ${ }^{1}$ Секция "Ендокринна хирургия", \\ Клиника по хирургия УМБАЛ "Царица Йоанна-ИСУЛ" \\ ${ }^{2}$ Клиника по УНГ-болести, УМБАЛ "Царица Йоанна-ИСУЛ"
}

\begin{abstract}
Резюме:
Ларингеалната дисфункция след тиреоидектомия е честа компликация. Парезата на нервус ларингеус рекуренс (НЛР) се нарежда сред водещите причини за медико-правни съдебни процеси срещу хирурзи в САЩ и ЕС. Основание за това е съпьтстващото нарушаване качеството на живот при пациента. Съобщаваме за 57-годишна пациентка с голяма рецидивна полинодозна струма. Болната е оперирана на 16.06.2008 в обем почти тотална тиреоидектомия. Извършена е билатерална идентификация и дисекция (невролиза) на рекурентните нерви. По време на невролизата е прекъсната целостта на левия НЛР и същият е възстановен посредством сутура с Prolene 7.0.

Хирургическата намеса е документирана с помощта на дигитална камера. Гласовата функция на пациентката е записана на 5 час, 24 час и 3 месеца постоперативно.

Една седмица след изписването при пациентката е извършена ларингостробоскопия в Сектора по фониатрия на УМБАЛ „Царица Йоанна-ИСУЛ“ - диагностицирана пареза на лява истинска гласна връзка. Пациентката е подложена на гласова рехабилитация. На 14. месец след тиреоидектомията резултатът от стробоскопията е невъзстановена функция на лява гласна връзка вследствие на перманентна пареза на левия НЛР.

Заключение: Интраоперативното възстановяване посредством сутура на прекъснат рекурентен нерв възстановява анатомично, но не и функционално нерва. Идентифицирането и последваща невролиза на НЛР са златният стандарт в тиреоидната хирургия. Това е най-добрата гаранция за запазване гласовата функция при болния.
\end{abstract}

Ключови думи: рекурентна пареза, тиреоидектомия.

\section{Abstract:}

Background: Laryngeal dysfunction after thyroidectomy is a common complication. Recurrent laryngeal nerve (RLN) palsy ranks among the leading reasons for medicolegal litigation of surgeons in USA and EU, because of its attendant reduction of quality of life.

\section{Въведение}

Парезата на нервус ларингеус рекуренс (НЛР) се нарежда сред водещите причини за медико-правни съдебни процеси срещу хирурзи в САЩ и ЕС. Увреждането на НЛР най-често причинява дисфония, усложнение, което може да намали общо качеството на живот при пациента поради социални, психологически и комуникационни проблеми $(1,2)$.

Честотата на рекурентните лезии в щитовидната хирургия варира между 0-7.1\% за преходните и 0-11\% за перманентните парези и се определя от: вида на тиреоидното заболяване, обема на резекция, опита на хирурга и прилаганата от него оперативна методика (3). През 2 век от н.е. Гален прьв описва детайлно рекурентните нерви. В началото на своята кариера, като хирург при гладиаторите в Пергамом, той наблюдава различни състояния вследствие увреждането на гласовите нерви. По-късно в Рим върху живи прасета Гален демонстрира пред високопоставени римляни функцията на описания от него възвратен нерв, заявявайки „Когато нервът бъде прекъснат, квиченето на прасето престава“" (5).

През 1938 г. Lahey в Boston и по-късно през 1956 г. Riddell в London въвеждат рутинната визуализация и дисекция на НЛР (т.нар. невролиза) при тиреоидни операции (6). Рутинната идентификация, невролиза при визуално проследяване на НЛР, както интраоперативният невромониторинг понастоящем са златният стандарт на тиреоидната хирургия в специализираните центрове на САЩ и ЕС. 
Case report: We report about 57-year-old female patient with big recurrent multi-nodular thyroid goiter. The patient was operated on 16.06.2008 - Near-total thyroidectomy et Visual bilateral Recurrent laryngeal nerve identification and preparation without the use of intraoperative nerve monitoring. During the preparation the left RLN has been damaged and a suture with Prolene 7.0 was performed. The surgical procedure was documented by camera. The patients voice function was recorded 5 hours, 24 hours and 3 months postoperatively.

An postoperative laryngostroboscopic examination was performed 1 week after discharge.

The patient underwent voice rehabilitation for a RLN paresis and was followed at the ENT- Phoniatric department.

Conclusion: Intraoperative suture of the injured laryngeal nerve bring less benefit for the RLN dysfunction.

Key words: Recurrent laryngeal nerve palsy, thyroidectomy.

\section{Клиничен случай}

Съобщаваме за 57-годишна пациентка с голяма рецидивна полинодозна струма. Болната е оперирана преди 14 години, настоящата намеса е извършена на 16.06.2008 г. - левостранна хемитиреоидектомия и разширена субтотална резекция на десен лоб. Екзактна, но изключително трудна идентификация на рекурентните нерви двустранно, на фона на множество сраствания от предходната операция. Десностранният НЛР, разположен пред основния клон на долната тиреоидна артерия, се разделя на два клона на мястото на de Quervain, където кръстосва А. thyreoidea inferior (Фиг. 1).

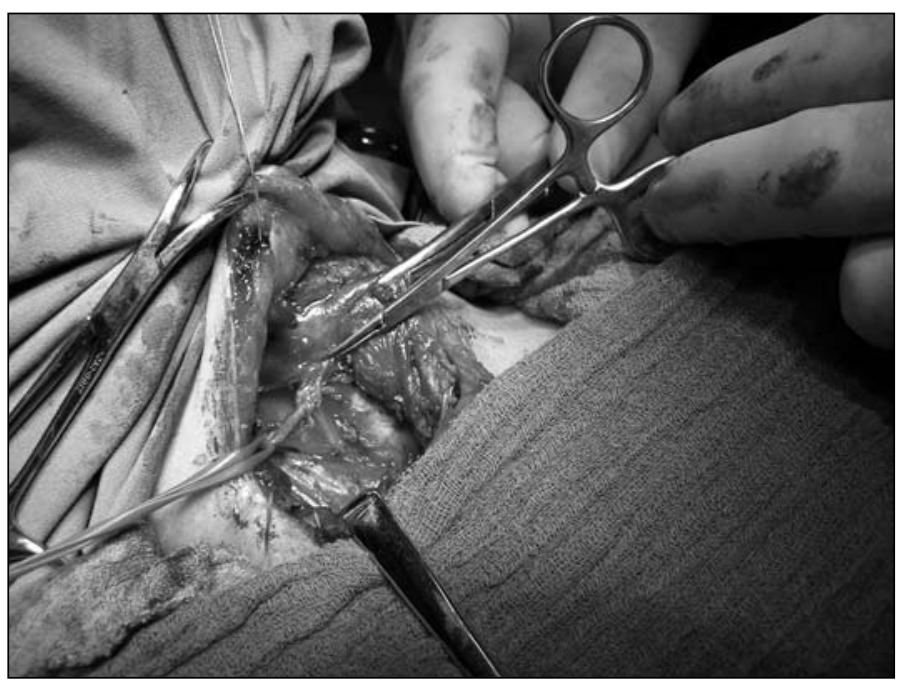

Фиг. 1.

Вляво по време на невролизата е прекъсната целостта на НЛР и същият е възстановен посредством атравматичен шев c Prolene 7.0 (Фиг. 2).

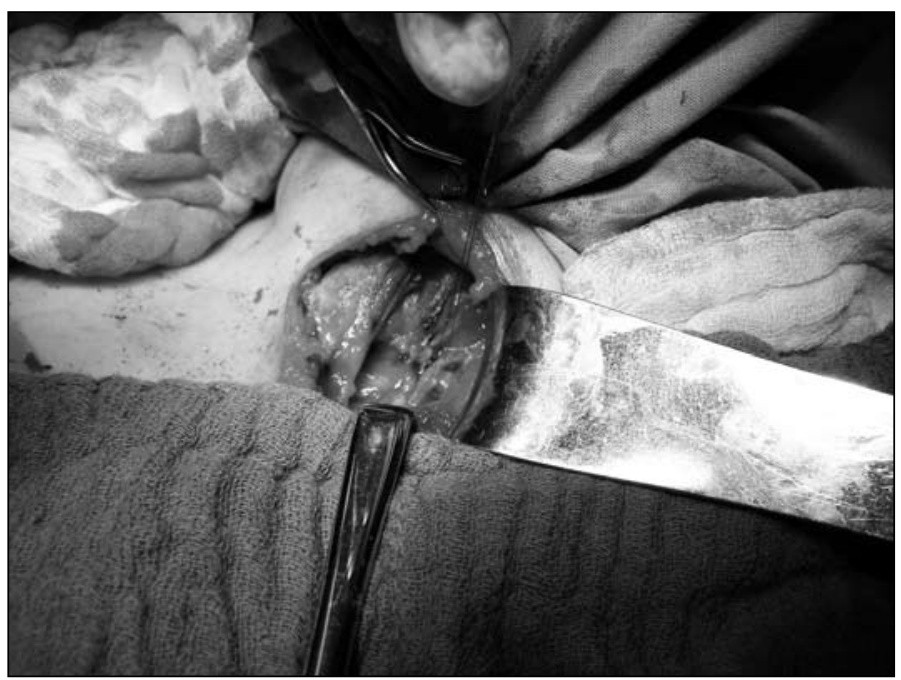

Фиг. 2. 
Хирургическата намеса е документирана с помощта на дигитална камера.

Гласовата функция при пациентката е записана в разговор с нея на 5 час, 2-я следоперативен ден и 3 месеца постоперативно (Фиг. 3).

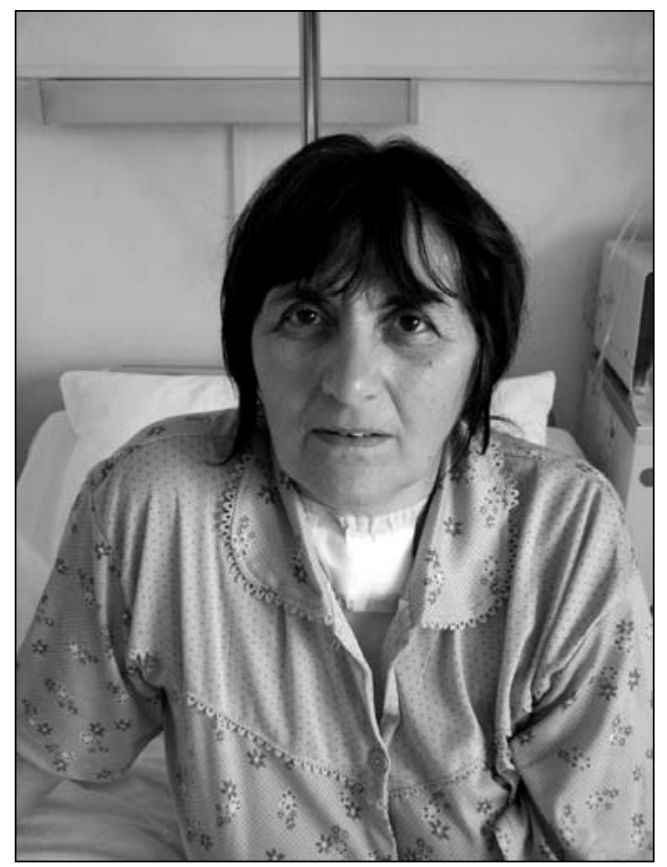

Фиг. 3.

Лека дисфония се появява след оперативната интервенция, без дисфагия или дихателни смущения. При консултация в Сектора по фониатрия на УМБАЛ „Царица Йоанна-ИСУЛ“ с индиректна ларингоскопия се установявят данни за неподвижна лява истинска гласна връзка при фонация и респирация в интермедиерно положение. Ларингостробоскопията показва данни за пареза от вял тип (фонаторна дискинезия с увеличени амплитуди на движение на лявата истинска гласна връзка - типична картина за лезия на нерва).

Перцептуалният слухов анализ показва данни за дисфония от втори тип, фонетографията установи намаляване на тоновия и силов диапазон. Време на максимална фонация 13 сек. при норма 20 сек. На пациентката след изписването е проведен курс по гласова рехабилитация: формиране на правилен тип фонационно дишане, фонаторни упражнения на твърда атака и активиране на резонаторите с взривни съгласни.

Контролният преглед след 6 месеца показа следните резултати:

- Ендоларингеална находка при индиректна ларингоскопия и ларингостробоскопия данни за вяла пареза на лявата истинска гласна гънка.
- Подробен акустичен анализ - дисфония първа степен, увеличаване на намаления тонов и силов диапазон и на времето на максимална фонация на 18 секунди. Препоръча се да продължи комплексьт от ежедневни специализирани упражнения с оглед предпазване от инактивираща хипотрофия на гласовата мускулатура в паретичната гласна връзка.

\section{Обсъждане}

Годишно в Германия се извършват 100000 тиреоидни операции. От тях 6000 са по повод рецидивни струми. При рецидивните намеси годишно се съобщава за 170-200 рекурентни парези. В Германия перманентната рекурентна пареза струва на осигурителната система 40000 евро, докато общите разходи по невромониторинга за един пациент не надхвърлят 2800 евро.

В повечето ендокринно хирургични звена на Германия интраоперативният невромониторинг не е правило, но визуалният мониторинг е облигатен. По повод невромониторинга Henning Dralle определя, че наличието само по себе си на даден апарат не гарантира неговата коректна употреба, нито прецизност на извършваната процедура (4, 8).

Визуалният мониторинг на НЛР (т.нар. невролиза) изисква между 10-30 минути по-дълго оперативно време за всеки един от рекурентните нерви (1).

След 2000 г. са налице законодателни промени в Германия и невролизата на НЛР е задължителна при извьршване на операции на щитовидната жлеза. През 2007 г. в една от немските провинции 16 пациенти предявяват иск в съда за обезщетение поради постоперативна дисфония, причинена от рекурентна лезия. При 8 от тях (50\%) съдебното решение е в ущърб на хирурга и в полза на пациента (4).

Още през 1938 г. след екзактна невролиза при 3000 пациенти Lahey отбелязва: „Екзактната дисекция на НЛР не увеличава, а намалява риска от рекурентна лезия.“ (6)

\section{Заключение}

Перифразирайки професор William Halsted, можем да кажем „най-добрата гаранция за перфектно извършена тиреоидектомия е запазване интегритета на рекурентния нерв“".

В България научната общност трябва ясно да дефинира, че извършването на тиреоидна хирургия е възможно само след екзактна невролиза на НЛР, наречен от Halsted-,,the wonderful nerve“ (7). 


\section{Библиография:}

1. R. Pandev, M. Welkov: Komplikationsrate verschiedener Operationstechniken bei den Schilddrüseneingriffen. Acta Chirurgica Austriaca 1996, 5, Suppl.123: 4

2. Т. Сечанов, Р. Пандев, Ю. Стойнов: Диагностични и клинични аспекти на постоперативните дисфонии след операции нащитовидната жлеза. Хиругия XLX 1997; № 5: 26-28.

3. Р. Пандев, Ю. Стойнов, Т Сечанов: Терапевтичен подход при постоперативните дисфонии след операции на щитовидната жлеза. Хиругия LV 1999; № 5: 26-28.

4. H. Dralle, C. Sekulla, K. Lorenz, M. Brauckhoff, A. Machens: Intraoperative Monitoring of the Recurrent Laryngeal Nerve in Thyroid Surgery. Wolrd J Surg 2008; 32: 1358-1366.
5. Duckworth WLH in: Lyons MC, Towers B(eds)- Galen on anatomical procedures: the later books. Cambridge University press, Cambridge 1962: p.81.

6. Lahey FH: Routine dissection and demonstration of the recurrent laryngeal nerve in subtotal thyroidectomy. Surg Gynecol Obstet. 1938; 66: 775-777.

7. Halsted WS: The operative story of goiter. The author's observation. The Johns Hopkins Hospital Report; 1920, vol 19.

8. Dralle H, Kruse E, Hamelmann WH et al: Nicht jeder Stimmlippenstillstand nach Schilddrusenoperation ist eine chirurgisch bedingte Rekurrensparese. Chirurg 2004; 75: 810-822.

\section{За кореспонденция:}

Д-р Румен Пандев дм

Университетска клиника по хирургия

Секция „Ендокринна хирургия“"

УМБАЛ „Царииа Йоанна -ИСУЛ“

Медицински университет София

$$
\begin{gathered}
\text { ул. „Бяло море“ " } 8 \\
1527 \text { София }
\end{gathered}
$$

e-mail:rumenpandev@yahoo.com

r.pandev@dir.bg 